\title{
Method of Writing Academic Articles based on Appraisal Study to Develop Language Curriculum
}

\author{
Agung Budi Kurniawan', Warsono ${ }^{2}$, Djoko Sutopo ${ }^{3}$, and Sri Wuli Fitriati ${ }^{4}$ \\ \{agungbudi430@yahoo.co.id ${ }^{1}$,warsono1103@gmail.com²,djoko.sutopo@mail.unnes.ac.id ${ }^{3}$, \\ \&SriWuli.Fitriati@mail.unnes.ac.id ${ }^{4}$ \} \\ 1,2,3,4 Pascasarjana Universitas Negeri Semarang, Indonesia
}

\begin{abstract}
The concept of this research is to develop a potential subject of writing academic article for publication to give contribution to the language curriculum development. The schema of writing is the development from IMRAD and AIMRaD. Every part of writing schema was formulated based on the data findings that were taken from Appraisal research to five journal articles in ELT. It was found that the method of writing introduction is to apply suggestion, pleasure, good intention, and avoid over repetition. The method of writing research method is to proclaim the security and give up-scale focus. The method of writing findings and discussion is to express positive appreciation, happiness, pleasure, satisfaction, to avoid stating negative justification, to ascertain readers for the originality of the findings, and to show the priority and uniqueness. The method of writing conclusion is to express personal perspective to the whole research process and result, and to emphasize the scientific values and benefits. It was concluded that writing academic article for publication needs serious attention.
\end{abstract}

Keywords: Writing, Publication, Appraisal, Curriculum

\section{INTRODUCTION}

The focus of this research is to study the recent academic obligation in the language especially English study program of college level. English students had been also required to publish their research result for a long time ago. It needs a new work system and skill. The work is "to write academic article that will be published in journal or proceeding". Of course, it needs certain knowledge and skills. In fact, writing final project is different with writing the publication article. The most visible is the number of pages and the material that is fewer than the final project. Commonly, students get more difficult to write the article because it must be informative, effective, and efficient in limited page and word number. The other obstacle is that every publisher of the article could give different rules and style of writing which is possible being different with the college or campus formal style of writing the final project. The last obstacle is that students cannot write the whole findings of the final project in the article, but they must select the material based on the certain criteria.

On the other hand, the interesting and interactive method of writing could increase students' motivation. It gives effect to increase the students' writing quality too. One investigation resulted that electronic writing as a new method could increase students' positive 
attitude and caused the communicative interaction [1]. Meanwhile, the additional data of a study presented indirectly that corpus method contributed to the students' academic and research writing [2]. It is why the characteristic of writing needs to be considered too. It is not only scientific values of the writing method, but also it is about how the method could attract students' intention. The writing method should also be joyful, understandable, and easy being practiced.

The study of how academic writing in the English college curriculum had been conducted successfully by some researchers. The gap between the concept and writing practice in ESL or EFL students must be bridged to improve the learners' writing skills [3]. The other study suggested that English literature study should be integrated into the curriculum to develop students' creativity in ESL writing [4]. Meanwhile, it was also found that writing across the curriculum in ELT influence the writing quality [5]. The study of English thesis writing suggested optimizing the English curriculum and making professional curriculum development to enhance the students' and teachers' ability [6]. The other fact showed that not all students had positive feeling and attitude towards writing in English [7]. It could be concluded that the material, arrangement of action, and target progress in the improvement of writing curriculum is very crucial to increase the output. The outputs are the writing ability of students, teachers, lectures, and the writing work in the publication. The last thing that must also be included to the improvement of English curriculum for the new subject concept is the improvement of view point and attitude to writing.

The study of preparing writing the academic and scientific article for publication had been conducted very well by some researchers. The first concept contains the outline which comprises title, abstract, introduction, body, discussion, reference with the aim is to provide early stage of essential practice and issue [8]. On the other hand, the variability in the methods, research topics, and approaches to inquiry was as the vital part in the writing plan and practice [9]. It also needs to be emphasized that the part of reviewing as the essential point in writing [10]. Those previous studies described how important the preparation and steps of writing.

Some researcher also studied the schema of writing an academic and scientific article in order to be published. One schema could comprise the title, authors, abstract, introduction, results and discussion, conclusion, and experimental [11]. The construction of writing schema could also comprise abstract, introduction, literature review, statement of the problem, method, result, and summary, discussion, and conclusion [12]. Then, one important schema applied in this research is called as IMRAD (introduction, method, results, and discussion) [13]. The second material of writing schema combination is called as AIMRaD (abstract, introduction, materials and methods, results, and discussion) [14]. In this research, researchers combined both of IMRAD, AIMRaD, and empiric data findings based on Appraisal application analysis to five articles in ELT. It was decided the scope of this study is introduction, method, findings and discussion, and conclusions. It is decided not to include the title and abstract because it is too fragile to propose both of them because every publisher has different style and content of title and abstract. Based on the findings, the title was usually written maximum into twelve word, the abstract contains 150-200 words, and the key words were usually required to include 3-5 words.

Appraisal is as one important component of this research. The concept of Appraisal is about the Interpersonal meaning study whose three main scopes of Attitude, Engagement, and Graduation [15]. The basic Appraisal branches are Attitude, Engagement, and Graduation [15]. Attitude concerned with our feeling. Engagement is the source of Attitudes that play voice in Discourse. Graduation refers to the grade of object or phenomena. They have very 
detailed system. In this research, researchers analyzed five articles in ELT for the whole Appraisal application.

Based on the background and theoretical review, researchers propose one research question which is "how is the method of writing an academic article for publication that covers the subject terminology, introduction, method, findings and discussion, and conclusions based on Appraisal study?". The objective of this study is to give positive contribution to the development of language curriculum.

Based on the result and discussion, this research proposed a new concept of method of writing academic paper for publication, benefit, and limitation. The new concept is the combination of IMRAD and AIMRad that builds the writing method schema which comprises defining subject terminology, method of writing introduction, research method, findings and discussion, and conclusions. The second new finding is that the new writing schema was constructed by conducting the Interpersonal meaning based on Appraisal. The benefit of this article is intended to the undergraduate language curriculum development. The limitation of this research is in the scope of constructing new method of writing academic paper for publication only. It was not purposed for other purposes.

\section{METHOD}

The method comprises the design, objects, instrument, technique of collecting and analyzing data. This research was conducted through contextual qualitative research. Contextual qualitative research terminology is as "describing the form or nature of what exist" [16]. This research proposes the nature of Appraisal application in the object as the material of constructing method of writing academic articles. The objects were five articles in ELT that were published in journals. The object type and quality represent the students' final task to publish their paper in journal. instrument is the Appraisal lexical list and concept. The technique of collecting and analyzing data followed the steps of the contextual qualitative design which were to map the element of the object, to display the specific feature of the element, to describe the meaning of the element and the supporting evidence, and to identify and define the typology that's related with the method of writing academic article [16].

\section{RESULT AND DISCUSSION}

The result and discussion were presented into five sessions. Evert part was explained comprehensively below. Every result was described comprehensively.

\subsection{The Subject Terminology}

Researchers propose the terminology as "writing the field research or study result of language application and implication in order to be published, read, and give benefits to language education practitioner". It has some implications. The limitation of "field research or study" is to limit the scope of "working result". It gives two choices which comprise the article as the result or field result or the result of reviewing theory. In this term, it is not intended to justify which one is better than the other. The second is that it must have language application and implication. It means that it is not allowed to exclude the language material in the research or study. It also indicated that the study must follow the recent trend, issue, and problem in language education. It is not recommended to study the old-concept material or over-used concept [17].

\subsection{Method of Writing Introduction}


The second session is the method of writing introduction. Based on the result of Appraisal application and implication in the object, it was identified some techniques to write introduction which combined the background with theoretical and previous studies review. In the end of introduction, it must be stated the statement or formulation of the problem.

In order to give good impression background, in term of attitude, writers need to suggest the topic of the research. Then, it needs to show the pleasure of satisfaction to the theory and the previous studies. It is the effective combination to persuade readers to agree indirectly with the topic. The expression of surprise and strong intention needs to be used with hedging because it could avoid getting arrogant and overconfident impression. Writers also should avoid totally writing narrative text. The argumentation and suggestion need to be preceded or followed by the relevant theories or previous studies. It is recommended to avoid the negative claim, statement, or expression such as unhappiness, displeasure, or giving negative judgment to the antithesis topic. It means that it could be applied for special cases, but in low frequency of use and use hedge. The last is to give positive appreciation to the theories and previous studies quotation.

In term of Engagement, the writing of background needs to be intended to be as close as with the readers. The first thing is the necessary to consider which one needs to be applied between denial and counter. It should be chosen one of them. The interesting background is to pronounce the original writers' idealism. Readers tend to search and be curious with the type and level of the writers' idealism. When giving and reviewing the theories of previous studies, writers have to be firm whether the statement is acknowledge or distance. It must not be ambivalence for the writers' position.

In the term of Graduation implication, it is very crucial because it is "how to build self image or impression in front of the readers view point". It is not recommended to use high frequency of repetition to state the main topic of the research because it will make the readers get boring quickly. The gradation of quality needs to be emphasized comprehensively for the theoretical and previous studies review. Readers should be ascertained that the choice of the references that is relevant with the research topic and the problem. Writers could also use the chronological order of occurrence to explain the history of the reference so that readers could understand the origin of the research topic.

\subsection{Method of Writing Research Method}

In the general concept and use, research method comprises the main information of the design, object, instrument, and technique of collecting and analyzing data. In term of Attitude, the statement tends to apply declaration of security. Researchers or writers tend to declare the type of the research design directly. It must include at least one reference of the research design. It is the declaration to apply the research design, object, instrument, and the technique. It is not recommended to review and give long explanation about the definition of the whole materials in the method. In term of Engagement, writers should apply the affirm of proclaim. They must be firm about the use of all materials. It is not suggested to ask readers to conclude by themselves. Writers must be responsible with the validity and consistency of the entire materials in the method. In the term of Graduation, writers have to give "up-scale" focus for every item. Writes must be confident enough with their choice in the method because it is how to conduct the research concept and got the result of data finding and analysis. In this case, it is suggested to give just one up-scale for every item, e.g. in the research design, writers must ascertain that the choice of the research design cannot be bargained because it is parallel with the problem identification in the introduction.

\subsection{Method of Writing Findings and Discussion}


Findings and discussion is usually the largest part in an article. It is caused to present what have got and what perspective to view the findings. It was explained one by one in term of Appraisal system which comprises Attitude, Engagement, and Judgment below.

In term of Attitude, writers should give good impression first to appreciate their findings by expressing happiness, proclaim, pleasure, satisfaction, or other positive value to the findings themselves. It is not recommended to express negative view to the findings. If it was done, readers will be doubt automatically with the article. They could get question how a writer or researcher could not give appreciation to his or her findings. The next application of attitude is judgment. In order to judge other person such as the research subject or other researchers, writers must still to give respect whether the judgment is positive or negative. When the subject is an expert, it needs to be more careful Attitude. In the vice versa, when the subject was in the lower level, the writers should still be humble. The other thing is that writers must avoid making controversy with the subject whose antithesis concept with the research topic. In giving Appreciation to the research findings, it's necessary to apply appropriate hedge. Naturally, writers would be proud of the findings, but it must be careful to give over confident of Appreciation. Writers should give just one till two criteria of appreciation. The use of over-criteria will make the readers to be curious with the truthfulness of the findings. In the discussion part, it also needs good negotiation technique to persuade readers to believe that the findings originally belong to the writers.

In term of Engagement, the point is how to present the data findings and discussion so that it could be understood by the readers easily. It is fragile to persuade readers to believe the originality of our data finding in this part. The point is to build comprehensive communication. In this writing method, writers could begin writing the pronounce or endorse statement first. It is not expected to state denial or counter directly. After giving the announcement, writers could continue applying the technique of entertain. It is suggested to apply the acknowledge if it is just necessary. The concept of acknowledge could ease the writing because it supports the analysis based on the experts' quotation. On the other hand, it could also give obstacle because it could be difficult to find quotation which will be similar totally with the findings. The writers must not force the irrelevant previous studies to be included in the discussion. It could confuse readers and decrease the scientific value. The choice and review of the theories and previous studies must have been clear and finished in the introduction chapter. The next, the application of counter to strengthen could be applied to avoid guessing. The fail of Engagement could make readers stop continuing reading the article.

In term of Graduation, the point is the necessary to differentiate the arrangement of the finding value from the highest to the lowest. It could also be from the smallest to the biggest, or vice versa. It is just a comparison. It means the writer must emphasize the most valuable part. It needs to give more frequency of discussion to the findings that's as the uniqueness of the research. The other emphasis is to the writer or researcher's rule in the process of collecting and analyzing data. The writers should show their activeness in collecting and analyzing the data finding no matter the type of the research design.

\subsection{Method of Writing Conclusions}

The basic view point is the controversy of presenting singular or plural or between conclusion and conclusions. Based on the findings of this research, it is recommended to present plural or more than one conclusion. We also found that the convenient conclusion is not to copy paste or rewrite the material in the background, method, and findings and discussion, but to create new ideas of the conclusion itself based on the whole research 
process and result. In term of Attitude, writers have to be honest with their perception to the main research process and result. It is highlighted the word of "main" because not all process and findings need to be concluded. It must be differentiated for the priority. In terms of Engagement, writers have to ensure the empiric value of the research or at least, the research is not imaginary or manipulation. If it is necessary, writers could suggest to the further researchers to duplicate or continue the research topic. In term of Graduation, writers should revise the most important part of the research process, result, and the contribution for the scope of the study.

\section{CONCLUSION}

There are three main conclusions based on the application and implication of this research. The first conclusion is about the contribution of linguistic study to the development of English curriculum. The contribution of applied linguistic could give contribution to the language education. It should be finished for the controversy, differentiating, even gap between language study branches whether language education, linguistic, literature, philosophies, etc. The second conclusion is the applicable and practicable aspect of method of writing academic article in this research. The combination of IMRAD and AIMRaD that built new schema which comprise determining the subject terminology, method of writing introduction, method of writing research method, method of writing findings and discussion, and method of writing conclusion could be applied directly to make students' article writing practice become more effective and efficient. The last conclusion is that Appraisal is one alternative method which is still possible to be combined with other linguistic study branches to develop the technique of writing academic articles. The Interpersonal meaning application to the new writing could make students develop their writing become more qualified.

\section{REFERENCE}

[1] A. Bustamante and M. Eom, "Linguistically Diverse Students' Attitudes Towards Writing in English," Texas J. Lit. Educ., vol. 5, no. 1, pp. 44-56, 2017.

[2] U. Römer and S. Wulff, "Applying corpus methods to written academic texts: Explorations of MICUSP,” J. Writ. Res., vol. 2, no. 2, pp. 99-127, 2010.

[3] S. H. Alharbi, "Principled Eclecticism: Approach and Application in Teaching Writing to ESL / EFL Students," English Lang. Teach., vol. 10, no. 2, pp. 33-39, 2017.

[4] B. Al-sobhi, S. Rashid, and A. N. Abdullah, "Arab ESL Secondary School Students " Attitude Toward English Spelling and Writing," Sage Journals, vol. 8, no. 1, pp. 1-11, 2018.

[5] M. Mussetta and A. Vartalatis, "Writing Across the Curriculum in ELT Training Courses: A Proposal Using Data-Driven Learning in Disciplinary Assignments," Int. J. Teach. Learn. High. Educ., vol. 30, no. 2, pp. 300-307, 2018.

[6] Y. Han, "An Analysis of Current Graduation Thesis Writing by English Majors in Independent Institute," English Lang. Teach., vol. 7, no. 1, pp. 120-127, 2014.

[7] I. H. Abas and N. H. A. Aziz, "Indonesian EFL Students ' Perspective on Writing Process : A Pilot Study,” Adv. Lang. Lit. Stud., vol. 7, no. 3, pp. 21-27, 2016.

[8] M. Derntl, "Basics of Research Paper Writing and Publishing," Int. J. Technol. Enhanc. Learn., vol. 6, no. 2, pp. 105-123, 2014.

[9] H. M. Levitt, M. Bamberg, J. W. Creswell, D. M. Frost, R. Josselson, and C. Suárezorozco, "Journal Article Reporting Standards for Qualitative Primary, Qualitative MetaAnalytic, and Mixed Methods Research in Psychology: The APA Publications and 
Communications Board Task Force Report," Am. Psychol., vol. 73, no. 1, pp. 26-46, 2018.

[10] B. Van Wee and D. Banister, "How to Write a Literature Review Paper ?," Transp. Rev., vol. 36, no. 2, pp. 278-288, 2016.

[11] G. M. Whitesides, "Whitesides â€ $€^{\mathrm{TM}}$ Group : Writing a Paper," Adv. Mater., vol. 16, no. 15, pp. 1375-1377, 2004.

[12] L. White, "Writes of Passage : Writing an Empirical Journal Article," J. Marriage Fam., vol. 67, no. 4, pp. 791-798, 2005.

[13] J. Hartley, Academic Writing and Publishing A Practical Handbook. New York: Routledge, 2008.

[14] M. Cargill and P. O'Connor, Writing Scientific Research Articles Strategy and Steps. West Sussex: Wiley-Blackwell, 2009.

[15] J. R. Martin and P. R. R. White, The Language of Evaluation Appraisal in English. New York: Palgrave Macmillan, 2005.

[16] J. Ritchie, "The Applications of Qualitative Methods to Social Research," in QUALITATIVE RESEARCH PRACTICE A Guide for Social Science Students and Researchers Edited, J. Ritchie and J. Lewis, Eds. London: SAGE Publications, 2003, pp. 24-46.

[17] K. Saddhono, N. E. Wardani, and C. Ulya. "Sociopragmatic approach on discourse structure of friday prayer's sermon in java and madura island." J. of Lang and Lit, vol. 6 no. 1 pp 26-29, 2015 